\title{
Atividade Proteolítica e Amonificante de vários tipos de solo do Estado de São Paulo. I. - Solo Latosol Vermelho Amarelo, com e sem cobertura morta $\left(^{*}\right)$
}

\author{
L. Neptune Ménard \\ E. S. A. «Luiz de Queiroz»
}

S. Joly

Instituto Zimotécnico

E. S. A. «Luiz de Queiroz»

* Recebido para publicação em $5 / 7 / 00$. 


\section{INTRODUÇÃO}

Iniciamos, com esta publicação, a primeira parte de uma série de trabalhos com os vários tipos de solo do Estado de São Paulo, começando com um solo Latosol Vermelho Amarelo existente na Escola Superior de Agricultura "Luiz de Queiroz", cuja classificação pedológica é devida a RANZANI (1958).**

A elaboração de novas técnicas após os estudos sôbre a fixação, a amonificação, a nitrificação e a desnitrificação, permitem visualizar melhor os fenômenos biológicos que se processam no solo.

WAKSMAN (1922) traçou o caminho e foi seguido por outros pesquisadores. Atualmente, a apreciação da fertilidade de um solo aparece como algo mais ou menos acessivel. Se bem é difícil afirmar a existência de causa e efeito no problema da relação da microflora e da fertilidade do solo, pode-se, entretanto, dizer que, quanto mais fértil o solo, maior a atividade da microflora total. Se considerarmos solos de natureza muito diversas, encontra-se uma relação bem definida entre a fertilidade aparente e a atividade biológica dos mesmos.

Os métodos microbiológicos, individualizando-se, completam os métodos usados em química agrícola e podem dar uma imagem bastante precisa do dinamismo biológico de um solo.

Neste trabalho o solo foi usado com a função de inóculo e de meio nutritivo. Desta forma, os resultados apresentam um reflexo da riqueza do solo em microrganismos capazes de efetuar a série de transformações biológicas, em benefício das plantas que se cultivam nesse solo. Nossa finalidade, ao realizar essa série de estudos, consiste em adotar um método que permita diferenciar dois tipos de solo sob o ponto de vista de sua atividade biológica e, conseqüentemente, da sua fertilidade aparente.

\section{MATERIAL E MÉTODOS}

\subsection{Método para medir a ațividade protelitica.}

\subsubsection{Fundamento do método.}

A quase totalidade do nitrogênio atualmente existente no solo está sob forma orgânica, protéica: nitrogênio, advindo da fixação, de tecidos animais e vegetais, de adubos verdes, estercos naturais, compostos; nitrogênio das reservas húmicas, elaboradas biològicamente no próprio solo. Todo êsse nitrogênio não pode ser utilizado dirétamente pelas plantas superiores, senão através de sua decom-

\footnotetext{
** Comunicação pessoal.
} 
posição pelos microrganismos do solo. Quando a matéria orgânica é adicionada ao solo, bactérias, leveduras, fungos, protozoários e outros organismos atacam os seus vários constituintes, degradando-os em compostos mais simples. A porção protéica da matéria orgânica, através da ação de enzimas proteoliticas dos microrganismos, é transformada em aminoácidos (CROCOMO e NEPTUNE MÉNARD, 1959). Partindo dêsse fato, podemos semear uma certa quantidade de solo com uma proteína e, após um período de incubação, dosar o grau de hidrólise dessa proteína.

\subsubsection{Técnica do método.}

A técnica adotada foi a de BROUWERS (1958)*, com ligeiras modificações. Prepara-se uma solução de gelatina a $10 \%$, distribuindo-se $20 \mathrm{ml}$ da mesma em frascos Erlenmeyer de $100 \mathrm{ml}$. Esteriliza-se a 1 atmosfera por 20 minutos. Semeia-se com solo. No nosso caso, usamos as seguintes quantidades: 1,0, 2,0 e 5,0 g. Foram testemunhas das respectivas quantidades, que sofreram esterilização após a inoculação. Depois de incubado a $35^{\circ} \mathrm{C}$ durante vários dias $(2,4,6$ e 8 dias $)$, retira-se, procede-se à centrifugação e, tomando-se $5 \mathrm{ml}$ do sobrenadante, acrescenta-se $5 \mathrm{ml}$ de uma solução de formaldeído, prèviamente neutralizado. Titula-se com uma solução de soda. O experimento foi realizado em duplicata.

Sendo o volume em $\mathrm{ml}$ de $\mathrm{NaOH}$ gasto para titular a gelatina hidrolizada e $\mathrm{Y}$ o volume em $\mathrm{ml}$ gasto para titular a testemunha, temos: $\mathrm{X}-\mathrm{Y}=\mathrm{I} \mathrm{p}$ (indice da atividade protelítica do solo).

\subsection{Método para medir a atividade amonificante.}

\subsubsection{Fundomento do método.}

Da degradação das proteínas no solo, resultam os diferentes aminoácidos. Estes, por sua vez, por influência da microflora, específica ou não, degradam-se em amoníaco, nitrito e nitrato. Inocula-se uma solução de aminoácido, com quantidades determinadas de um solo: após a incubação é medido o grau de decomposição do aminoácido.

\subsubsection{Técnica do método.}

Prepara-se uma solução de glicina a 5\% e distribui-se em tubos de cultura, $5 \mathrm{ml}$ em cada. Acrescente-se a quantidade de solo necessária, No caso usamos 0,5, 1,0 e 2,0 g. Após incubação a $28^{\circ} \mathrm{C}$ por $2,4,6$ e 8 dias, junta-se $5 \mathrm{ml}$ de água destilada,

* Comunicação pessoal. 
seguindo a técnica anterior. Seja $\mathrm{Y}$ o volume em $\mathrm{ml}$ de $\mathrm{NaOH}$ gasto para titular a testemunha estéril e $X$ o volume em $\mathrm{ml}$ gasto para titular a solução de glicina degradada, temos então : $\mathrm{Y}-\mathrm{X}$ - Ia (índice da atividade amonificante).

\subsection{Amostragem.}

Trabalhamos com amostras compostas para evitar quanto possível o efeito da heterogeneidade do solo.

As amostras foram tiradas em duas profundidades diferentes: uma superficial, de 0-2 cm; outra de 0-20 cm. Essas mostras provêm de um solo Latosol Vermelho Amarelo, cultivado com cafeeiro, com dois tratamentos diferentes: um com cobertura morta e outro sem cobertura morta. Querendo evitar certas perturbações no equilibrio da microflora do solo, resolvemos não deixar secar ao ar essas mesmas amostras, conforme recomendam vários autores e, por isso, peneiramos em tamis n. ${ }^{\circ} 10$, malha $1,651 \mathrm{~mm}$, colocando em caixa de Petri e deixando em câmara úmida. Esta foi conseguida usando um dessecador provido de um vaso com água. Êsse processo revelou-se bastante satisfatório. Foi tirado o teor de umidade das diferentes amostras antes de cada pesagem.

\begin{tabular}{|c|c|c|c|}
\hline \multicolumn{2}{|r|}{ Solo } & $\begin{array}{l}\text { Profundidade } \\
\text { em cm }\end{array}$ & $\begin{array}{l}\text { Teor de umi- } \\
\text { dade em \% }\end{array}$ \\
\hline \multicolumn{2}{|c|}{ Com cobertura morta } & $0-2$ & 27,6 \\
\hline Sem & $"$ & $0-2$ & 5,0 \\
\hline Sem & $"$ & $0-20$ & 14,8 \\
\hline Com & $"$ & 0.20 & 9,3 \\
\hline
\end{tabular}

2.4. Análise quimica.

As análises químicas foram efetuadas de acôrdo com os métodos estabelecidos por CATANI et al. (1955).

\subsection{Contagem da população microbiana.}

Foram realizadas diluições de $10^{-1}$ a $10^{-8}$ e, daí o material foi semeado em caixa de Petri com meio nutritivo apropriado; após o desenvolvimento das colônias, procedeu-se à contagem, que permitiu o resultado que aparece no Quadro IV. 


\section{RESULTADOS OBTIDOS}

Os resultados do presente trabalho são apresentados nos quadros e gráficos abaixo.

\subsection{Análise quimica.}

QUADRO IJ

Solo: Profundidade, $0-20 \mathrm{~cm}$

\begin{tabular}{|c|c|c|c|c|}
\hline \multirow{2}{*}{ Característica } & \multicolumn{2}{|c|}{ Com cobertura } & \multicolumn{2}{|c|}{ Sem cobertura } \\
\hline & Valor & Interpretação & Valor & Interpretảção \\
\hline & & aciclez média & 5,7 & acidez média \\
\hline Mat. orgânica \% & 1,032 & teor baixo & 0,772 & teor baixo \\
\hline $\mathrm{PO}_{4}-^{3} \mathrm{em} \mathrm{e} \mathrm{mg}$ & 0,048 & $"$ alto & 0,120 & " médio \\
\hline $\mathrm{K}+$ trocável em & & " baixo & 0,031 & $"$ baixo \\
\hline $\mathrm{Ca} t^{\mathrm{e}} \cdot \underset{\text { trocável }}{\mathrm{mg}}$ & 1,350 & $"$ alto & 0,513 & $"$ alto \\
\hline em e. $\mathrm{mg}$ & 5,1 & " alto & 7,3 & $"$ alto \\
\hline
\end{tabular}

QUADRO III

Solo: Profundidarle, $0-2 \mathrm{~cm}$

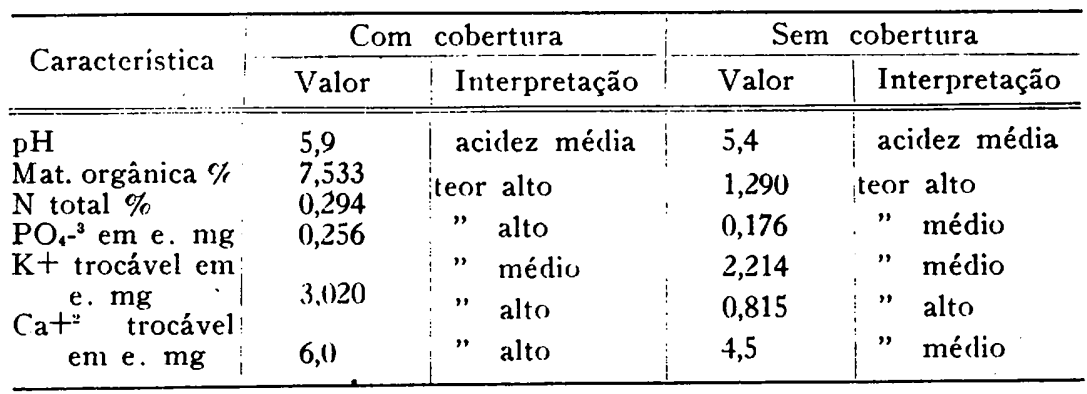

3.2. Contagem da população total.

QUADRO IV

\begin{tabular}{|c|c|c|}
\hline Solo & $\begin{array}{l}\text { Profundidade } \\
\mathrm{em} \mathrm{cm}\end{array}$ & $\begin{array}{l}\text { N.o de células } \\
\text { por g de solo }\end{array}$ \\
\hline $\begin{array}{l}\text { Com cobertura morta } \\
\text { Sem } \\
\text { Sem } \\
\text { Com } " ~\end{array}$ & $\begin{array}{l}0-20 \\
0-20 \\
0-2 \\
0-2\end{array}$ & $\begin{array}{c}5.446 .009 \\
2.138 .930 \\
40.386 .740 \\
12.526 .315\end{array}$ \\
\hline
\end{tabular}




\subsection{Resultado da atividade proteolitica do solo em estudo.}

QUADRO V

Atividade proteolítica de um solo Latosol Vermelho Amarelo

\begin{tabular}{|c|c|c|c|c|c|c|c|}
\hline \multirow{2}{*}{$\begin{array}{l}\text { Tempo } \\
\text { de } \\
\text { incuba- } \\
\text { ção }\end{array}$} & \multirow{2}{*}{$\begin{array}{c}\text { Quanti- } \\
\text { dade de } \\
\text { solo } \\
\text { em } g\end{array}$} & \multicolumn{3}{|c|}{$\begin{array}{l}\text { Com coivertura morta } \\
\text { Profundidade: } 0-20 \mathrm{~cm}\end{array}$} & \multicolumn{3}{|c|}{$\begin{array}{l}\text { Sem cobertura morta } \\
\text { Profundidade: } 0-20 \mathrm{~cm}\end{array}$} \\
\hline & & $\begin{array}{c}\mathrm{ml} \mathrm{de} \\
\mathrm{NaOH} \\
0,1 \quad \mathrm{~N}\end{array}$ & Média & $\begin{array}{l}\text { Indice } \\
\text { proteo- } \\
\text { lítico } \\
\text { (Ip) }\end{array}$ & $\begin{array}{l}\mathrm{ml} \mathrm{de} \\
\mathrm{NaOH} \\
\mathrm{O}, \mathrm{I} \mathrm{N}\end{array}$ & Média & $\begin{array}{l}\text { Indice } \\
\text { proteo- } \\
\text { lítico } \\
\text { (II) }\end{array}$ \\
\hline & $\begin{array}{l}1,0 \mathrm{~g} \\
\text { Teste- } \\
\text { munha }\end{array}$ & $\begin{array}{r}2,7 \\
2,8 \\
-2,8\end{array}$ & 2,7 & & $\begin{array}{r}2,8 \\
2,8 \\
\end{array}$ & 2,8 & \\
\hline 2 dias & & $\begin{array}{r}3,0 \\
3,0 \\
.\end{array}$ & 3,0 & 0,3 & $\begin{array}{l}2,9 \\
2,9\end{array}$ & 2,9 & 0,1 \\
\hline 4 dias & & $\begin{array}{l}7,0 \\
7,1 \\
\end{array}$ & 7,1 & 4,4 & $\begin{array}{l}6,3 \\
6,1\end{array}$ & 6,2 & 3,4 \\
\hline 6 dias & & $\begin{array}{l}16,0 \\
16,4\end{array}$ & 16,2 & 13,5 & $\begin{array}{l}12,0 \\
12,6\end{array}$ & 12,3 & 9,5 \\
\hline 8 dias & & $\begin{array}{l}26,6 \\
26: 2 \\
\end{array}$ & 26,4 & 23.7 & $\begin{array}{l}21,6 \\
22,4 \\
\end{array}$ & 22,0 & 19,2 \\
\hline & $\begin{array}{l}2,0 \mathrm{~g} \\
\text { Teste- } \\
\text { munha }\end{array}$ & $\begin{array}{l}2,4 \\
2,3\end{array}$ & 2,4 & $\begin{array}{l}2,4 \\
2,8\end{array}$ & 2,6 & & \\
\hline 2 dias & - & $\begin{array}{l}3,2 \\
3.4 \\
\end{array}$ & 3,3 & 0,9 & $\begin{array}{l}3,1 \\
3,2 \\
\end{array}$ & 3,2 & 0,6 \\
\hline 4 dias & & $\begin{array}{r}8,6 \\
9,4 \\
\end{array}$ & 9,0 & 6,6 & $\begin{array}{r}7,8 \\
8,2\end{array}$ & 8,0 & 5,4 \\
\hline 6 dias & & $\begin{array}{l}21,0 \\
20,6\end{array}$ & 20,3 & 18,4 & $\begin{array}{l}16,8 \\
17,0\end{array}$ & 16,9 & 14,3 \\
\hline 8 dias & & $\begin{array}{l}28,8 \\
28,4 \\
\end{array}$ & 28,6 & 25,9 & $\begin{array}{l}26,2 \\
25,8 \\
\end{array}$ & 26.0 & 23,2 \\
\hline & $\begin{array}{l}5,0 \mathrm{~g} \\
\text { Teste- } \\
\text { munha }\end{array}$ & $\begin{array}{l}2,4 \\
2,2 \\
\end{array}$ & 2,3 & & $\begin{array}{l}2,3 \\
2,3\end{array}$ & 2,3 & \\
\hline 2 dias & & $\begin{array}{r}3,7 \\
3,8 \\
\end{array}$ & 3,8 & 1,5 & $\begin{array}{l}3,5 \\
3,6 \\
\end{array}$ & 3,6 & 1,3 \\
\hline 4 dias & & $\begin{array}{r}12,9 \\
12,3 \\
\end{array}$ & 12,6 & 10,3 & $\begin{array}{l}11,8 \\
11,6 \\
\end{array}$ & 11,7 & 9.4 \\
\hline 6 dias & & $\begin{array}{r}24,0 \\
25,6 \\
\end{array}$ & 24,8 & 22,5 & 22,1 & 21,9 & 18,6 \\
\hline 8 dias & & $\begin{array}{l}34,2 \\
34,6 \\
\end{array}$ & 34,4 & 32,1 & $\begin{array}{l}32,4 \\
33,0 \\
\end{array}$ & 32.7 & 30,4 \\
\hline
\end{tabular}


QUADRO VI

Atividade proteolítica de um solo Latosol Vermelho Amarelo

\begin{tabular}{|c|c|c|c|c|c|c|c|}
\hline \multirow{2}{*}{$\begin{array}{l}\text { Tempo } \\
\text { de } \\
\text { incuba- } \\
\text { ção }\end{array}$} & \multirow{2}{*}{$\begin{array}{l}\text { Quanti- } \\
\text { dade de } \\
\text { solo } \\
\text { em g }\end{array}$} & \multicolumn{3}{|c|}{$\begin{array}{l}\text { Com cobertura morta } \\
\text { Profundidade: } 0-20 \mathrm{~cm}\end{array}$} & \multicolumn{3}{|c|}{$\begin{array}{l}\text { Sem cobertura morta } \\
\text { Profundidade: } 0-20 \mathrm{~cm}\end{array}$} \\
\hline & & $\begin{array}{l}\mathrm{ml} \mathrm{de} \\
\mathrm{NaOH} \\
0, \mathrm{I} \mathrm{N}\end{array}$ & Média & $\begin{array}{l}\text { Indice } \\
\text { proteo- } \\
\text { litico } \\
\text { (Ip) }\end{array}$ & $\begin{array}{l}\mathrm{ml} \mathrm{de} \\
\mathrm{NaOH} \\
\mathrm{o}, \mathrm{I} \mathrm{N}\end{array}$ & Média & $\begin{array}{l}\text { Indice } \\
\text { proteo- } \\
\text { lítico } \\
\text { (Ip) }\end{array}$ \\
\hline & $\begin{array}{l}1,0 \mathrm{~g} \\
\text { Teste- } \\
\text { munha }\end{array}$ & $\begin{array}{l}2,5 \\
2,7 \\
\end{array}$ & 2,6 & & $\begin{array}{l}2,5 \\
2,7 \\
\end{array}$ & 2,6 & \\
\hline 2 dias & & $\begin{array}{l}13,4 \\
12,4 \\
\end{array}$ & 12,9 & 10,3 & $\begin{array}{l}5,6 \\
5,2 \\
\end{array}$ & 5,4 & 2,8 \\
\hline 4 dias & & $\begin{array}{l}37,7 \\
34,3\end{array}$ & 36,0 & 33,4 & $\begin{array}{l}18,2 \\
17,6\end{array}$ & 17,9 & 15,3 \\
\hline 6 dias & & $\begin{array}{l}40,3 \\
39,5\end{array}$ & 39,9 & 37,3 & $\begin{array}{l}27,2 \\
25,9\end{array}$ & 26,5 & 23,9 \\
\hline 8 dias & & $\begin{array}{l}43,3 \\
42,7 \\
\end{array}$ & 43,0 & 40,4 & $\begin{array}{l}38,0 \\
37,6 \\
\end{array}$ & 37,8 & 35,2 \\
\hline & $\begin{array}{l}2,0 \mathrm{~g} \\
\text { Teste- } \\
\text { munha }\end{array}$ & $\begin{array}{l}2,6 \\
2,6 \\
\end{array}$ & 2,6 & & $\begin{array}{l}2,6 \\
2,5\end{array}$ & 2,6 & \\
\hline 2 dias & & $\begin{array}{l}17,2 \\
17,6 \\
\end{array}$ & 16,4 & 14,8 & $\begin{array}{l}5,7 \\
5,9\end{array}$ & 5,8 & 3,2 \\
\hline 4 dias & & $\begin{array}{l}36,7 \\
34,3\end{array}$ & 35,5 & 32,9 & $\begin{array}{l}19,5 \\
19,9\end{array}$ & 19,7 & 17,1 \\
\hline 6 dias & & $\begin{array}{l}39,3 \\
37,9\end{array}$ & 38,6 & 36,0 & $\begin{array}{l}33,2 \\
34,6\end{array}$ & 33,9 & 31,3 \\
\hline 8 dias & & $\begin{array}{l}39,0 \\
39,2 \\
\end{array}$ & 39,1 & 36,5 & $\begin{array}{l}37,0 \\
39,2 \\
\end{array}$ & 38,1 & 35,5 \\
\hline & $\begin{array}{l}5,0 \mathrm{~g} \\
\text { Teste- } \\
\text { munha }\end{array}$ & $\begin{array}{l}3,0 \\
2,8\end{array}$ & 2,9 & & $\begin{array}{l}2,4 \\
2,5\end{array}$ & 2,5 & \\
\hline 2 dias & & $\begin{array}{l}18,6 \\
17,8\end{array}$ & 18,2 & 15,3 & $\begin{array}{l}6,0 \\
5,8 \\
\end{array}$ & 5,9 & 3,4 \\
\hline 4 dias & & $\begin{array}{l}24,7 \\
31,2 \\
\end{array}$ & 27,9 & 24,7 & $\begin{array}{l}21,8 \\
20,6 \\
\end{array}$ & 21,2 & 18,7 \\
\hline 6 dias & & $\begin{array}{l}33,4 \\
31,8\end{array}$ & 32,6 & 31,2 & $\begin{array}{l}31,7 \\
31,3\end{array}$ & 31,5 & 29,0 \\
\hline 8 dias & & $\begin{array}{l}38,5 \\
34,7\end{array}$ & 36,5 & 33,6 & $\begin{array}{l}36,4 \\
34,3\end{array}$ & 35,4 & 32,9 \\
\hline
\end{tabular}


3.4. Resultado da atividade amonificante do solo em estudo.

QUADRO VII

Atividade amonificante de um solo tatosol Vermelho Amarelo

\begin{tabular}{|c|c|c|c|c|c|c|c|}
\hline \multirow{2}{*}{$\begin{array}{c}\text { Tempo } \\
\text { de } \\
\text { incuba- } \\
\text { ção }\end{array}$} & \multirow{2}{*}{$\begin{array}{l}\text { Quanti- } \\
\text { dade de } \\
\text { solo } \\
\text { em } g\end{array}$} & \multicolumn{3}{|c|}{$\begin{array}{l}\text { Com cobertura morta } \\
\text { Profundidade: } 0-20 \mathrm{~cm}\end{array}$} & \multicolumn{3}{|c|}{$\begin{array}{l}\text { Sem cobertura morta } \\
\text { Profundidade: } 0-20 \mathrm{~cm}\end{array}$} \\
\hline & & $\begin{array}{l}\mathrm{ml} \text { de } \\
\mathrm{NaOH} \\
\mathrm{o}, 1 \mathrm{~N}\end{array}$ & Média & $\begin{array}{c}\text { Indice } \\
\text { proteo- } \\
\text { lítico } \\
\text { (Ip) } \\
\end{array}$ & $\begin{array}{c}\mathrm{ml} \mathrm{de} \\
\mathrm{NaOH} \\
0,1 \mathrm{~N}\end{array}$ & Média & $\begin{array}{l}\text { fndice } \\
\text { proteo- } \\
\text { litico } \\
\text { (Ip) }\end{array}$ \\
\hline & $\begin{array}{l}1,0 \mathrm{~g} \\
\text { Teste- } \\
\text { munha }\end{array}$ & $\begin{array}{l}17,0 \\
17,2 \\
\end{array}$ & 17,1 & & $\begin{array}{l}17,9 \\
17,5\end{array}$ & 17,7 & \\
\hline 2 dias & & $\begin{array}{l}16,6 \\
15,8 \\
\end{array}$ & 16,4 & 0,7 & $\begin{array}{l}16,9 \\
16,5\end{array}$ & 16,7 & 1,0 \\
\hline 4 dias & & $\begin{array}{l}15,8 \\
15,9\end{array}$ & 15,9 & 1,2 & $\begin{array}{l}15, \overline{9} \\
15,9\end{array}$ & 15,9 & 1,8 \\
\hline 6 dias & & $\begin{array}{l}13,6 \\
14,2 \\
\end{array}$ & 13,9 & 3,2 & $\begin{array}{l}15,5 \\
15,9 \\
\end{array}$ & 15,7 & 2,0 \\
\hline 8 dias & & $\begin{array}{l}14,8 \\
14,2 \\
\end{array}$ & 14,5 & 2,6 & $\begin{array}{l}16,2 \\
15,6 \\
\end{array}$ & 15,9 & 1,8 \\
\hline & $\begin{array}{l}2,0 \mathrm{~g} \\
\text { Teste- } \\
\text { munha }\end{array}$ & $\begin{array}{l}15,7 \\
16,1 \\
\end{array}$ & 15,9 & & $\begin{array}{l}16,8 \\
17,4\end{array}$ & 17,1 & \\
\hline 2 dias & & $\begin{array}{l}14,8 \\
14,6\end{array}$ & 14,7 & 1,2 & $\begin{array}{l}16,1 \\
15,9\end{array}$ & 16,0 & 1,1 \\
\hline 4 dias & & $\begin{array}{l}14,7 \\
14,5\end{array}$ & 14,6 & 1,3 & $\begin{array}{l}15,5 \\
15,5\end{array}$ & 15,5 & 1,6 \\
\hline 6 dias & & $\begin{array}{l}9,2 \\
8,6 \\
\end{array}$ & 8,9 & 7,0 & $\begin{array}{l}14,2 \\
14,8\end{array}$ & 14,5 & 2,6 \\
\hline 8 dias & & $\begin{array}{r}9,7 \\
9,5 \\
\end{array}$ & 9,6 & 6,3 & $\begin{array}{l}14,9 \\
14,7 \\
\end{array}$ & 14,8 & 2,3 \\
\hline & $\begin{array}{l}5,0 \mathrm{~g} \\
\text { Teste- } \\
\text { munha } \\
\end{array}$ & $\begin{array}{l}13,0 \\
13,2\end{array}$ & 13,1 & & $\begin{array}{l}16,0 \\
16,6\end{array}$ & 16,3 & \\
\hline 2 dias & & $\begin{array}{r}12,2 \\
11,6 \\
\end{array}$ & 11,9 & 1,2 & $\begin{array}{l}14,5 \\
14,3 \\
\end{array}$ & 14,4 & 1,9 \\
\hline 4 dias & & $\begin{array}{r}9,9 \\
10,7\end{array}$ & 10,3 & 2,8 & $\begin{array}{l}13,7 \\
13,5 \\
\end{array}$ & 13,6 & 2,7 \\
\hline 6 dias & & $\begin{array}{l}6,8 \\
6,4 \\
\end{array}$ & 6,6 & 6,5 & $\begin{array}{l}12,4 \\
13,0\end{array}$ & 12,7 & 3,6 \\
\hline 8 dias & & $\begin{array}{l}7,7 \\
8,9 \\
\end{array}$ & 8,3 & 4,8 & $\begin{array}{l}12,8 \\
13,4 \\
\end{array}$ & 13,1 & 3,2 \\
\hline
\end{tabular}


QUADRO VIII

Atividade amonificante de um solo Latosol Vermelho Amarelo

\begin{tabular}{|c|c|c|c|c|c|c|c|}
\hline \multirow{2}{*}{$\begin{array}{l}\text { Tempo } \\
\text { de } \\
\text { incuba- } \\
\text { ção }\end{array}$} & \multirow{2}{*}{$\begin{array}{l}\text { Quanti- } \\
\text { dade de } \\
\text { solo } \\
\text { em g }\end{array}$} & \multicolumn{3}{|c|}{$\begin{array}{l}\text { Com cobertura morta } \\
\text { Profundidacle: } 0-20 \mathrm{~cm}\end{array}$} & \multicolumn{3}{|c|}{$\begin{array}{l}\text { Sem cobertura morta } \\
\text { Profundidade: } 0-20 \mathrm{~cm}\end{array}$} \\
\hline & & $\begin{array}{c}\mathrm{ml} \text { de } \\
\underset{\mathrm{NaOH}}{\mathrm{N}}\end{array}$ & Média & $\begin{array}{l}\text { Indice } \\
\text { proteo- } \\
\text { lítico } \\
(\text { Ip) }\end{array}$ & $\begin{array}{l}\mathrm{ml} \mathrm{de} \\
\mathrm{NaOH} \\
\mathrm{o}, \mathrm{I} \mathrm{N}\end{array}$ & Média & $\begin{array}{c}\text { Indice } \\
\text { proteo- } \\
\text { litico } \\
\text { (Ip) }\end{array}$ \\
\hline & $\begin{array}{l}1,0 \mathrm{~g} \\
\text { Teste- } \\
\text { munha }\end{array}$ & $\begin{array}{l}17,0 \\
17,2\end{array}$ & 17,1 & & $\begin{array}{l}18,5 \\
17,7\end{array}$ & 18,1 & \\
\hline 2 dias & & $\begin{array}{l}17,4 \\
17,6\end{array}$ & 17,5 & 0,4 & $\begin{array}{l}17,2 \\
16,9\end{array}$ & 17,0 & 1,1 \\
\hline 4 dias & & $\begin{array}{l}13,4 \\
13,8\end{array}$ & 13,6 & 3,5 & $\begin{array}{l}16,1 \\
14,1\end{array}$ & 15,1 & 3,0 \\
\hline 6 dias & & $\begin{array}{r}10,9 \\
9,9 \\
\end{array}$ & 10,4 & 6,7 & $\begin{array}{l}14,9 \\
13,7\end{array}$ & 14,3 & 3,8 \\
\hline 8 dias & . & $\begin{array}{l}10,2 \\
11,0 \\
\end{array}$ & 10,6 & 6,5 & $\begin{array}{l}15,0 \\
15,0 \\
\end{array}$ & 15,0 & 3,1 \\
\hline & $\begin{array}{l}2,0 \mathrm{~g} \\
\text { Teste- } \\
\text { munha }\end{array}$ & $\begin{array}{l}15,3 \\
16,3\end{array}$ & 15,8 & & $\begin{array}{l}17,2 \\
16,6\end{array}$ & 16,9 & \\
\hline 2 dias & & $\begin{array}{l}15,0 \\
15,0\end{array}$ & 15,0 & 0,8 & $\begin{array}{l}16,5 \\
16,5\end{array}$ & 16,5 & 0,4 \\
\hline 4 dias & & $\begin{array}{l}8,5 \\
8,6 \\
\end{array}$ & 8,5 & 7,3 & $\begin{array}{l}15,0 \\
14,8 \\
\end{array}$ & 14,9 & 2,0 \\
\hline 6 dias & & $\begin{array}{l}7,2 \\
6,2 \\
\end{array}$ & 6,7 & 9,1 & $\begin{array}{l}10,2 \\
10,1 \\
\end{array}$ & 10,1 & 6,8 \\
\hline 8 dias & & $\begin{array}{r}10,1 \\
8,0 \\
\end{array}$ & 9,1 & 6,7 & $\begin{array}{l}11,2 \\
11,1\end{array}$ & 11,2 & 5.7 \\
\hline & $\begin{array}{l}5,0 \mathrm{~g} \\
\text { Teste- } \\
\text { munha }\end{array}$ & $\begin{array}{l}13,4 \\
13,6 \\
\end{array}$ & 13,5 & & $\begin{array}{l}16,3 \\
16,5\end{array}$ & 16,4 & \\
\hline 2 dias & & $\begin{array}{l}13,1 \\
13,0\end{array}$ & 13,0 & 0,5 & $\begin{array}{l}16,0 \\
16,0\end{array}$ & 16,0 & 0,4 \\
\hline 4 dias & & $\begin{array}{l}6,5 \\
6,9\end{array}$ & 6,7 & $, 6,8$ & $\begin{array}{l}11,6 \\
13,6\end{array}$ & 12,6 & 3,8 \\
\hline 6 dias & & $\begin{array}{l}5,6 \\
4,9 \\
\end{array}$ & 5,3 & 8,2 & $\begin{array}{r}10,5 \\
9,7 \\
\end{array}$ & 10,1 & 6,3 \\
\hline 8 dias & & $\begin{array}{l}6,7 \\
6,2\end{array}$ & 6,4 & 7,1 & $\begin{array}{l}9,6 \\
9,2\end{array}$ & 9,4 & 5,0 \\
\hline
\end{tabular}

3.5. Resultado do indice protelitico do solo em estudo. (Gráfico I e II).

3.6. Resultado do indice amonificante do solo em estudo. (Gráfico III e IV). 

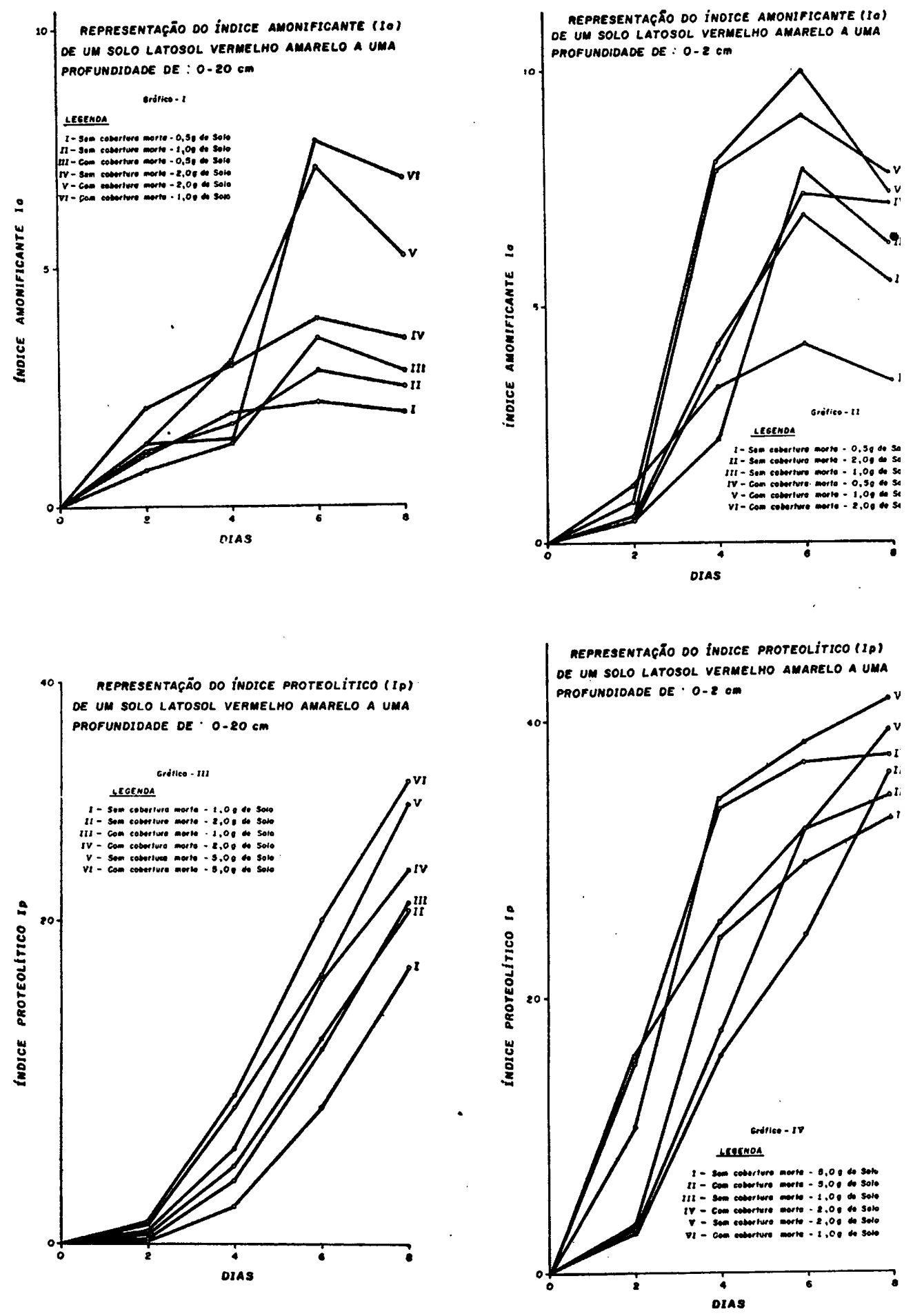


\section{DISCUSSÃO DOS RESULTADOS}

Não é sem motivo que escolhemos um solo da mesma origem pedológica, mas com tratamento diferente. A cobertura morta tem uma importância capital no problema da conservação e da regeneração dos solos tropicais. A ação benéfica da cobertura morta manifesta-se por uma melhor retenção da umidade, por um aumento da atividade biológica, por uma melhor utilização de adubos minerais pelas plantas e por uma melhor conservação do solo. Observando o Quadro I, pode-se notar a diferença nítida entre os teores de umidade nos dois tratamentos; é de salientar que o experimento ocorreu durante os meses de Junho e Julho, meses em que a precipitação pluviométrica foi nula.

O solo em questão é ácido e não muito pobre, como se pode ver no Quadro II.

Examinando o Quadro III, nota-se um abaixamento do $\mathrm{pH}$ e teor elevadissimo em matéria orgânica e $\mathrm{K}^{+}$trocácel no solo com cobertura morta.

Embora o solo acuse um pH baixo, as análises químicas revelam um teor em $\mathrm{Ca}++$ trocável mais alto que os outros catiônicos; êsse fenômeno ocorre nos solos do Estado de São Paulo.

Os resultados da contagem da população da microflora total mostrando a profícua atividade biológica do solo, evidenciam ainda mais a importância da cobertura morta.

Além das diferenças patentes entre as atividades biológicas do solo com e sem cobertura morta, e à profundidade de 0-2 e $0-20 \mathrm{~cm}$, é preciso ressaltar as variações regulares e lógicas das curvas, em função da quantidade de solo e do tempo de incubação. (Ver Quadros V, V, VII e VIII, e Gráficos I, II, III e IV).

Nos Gráficos II e III observa-se, nos dois primeiros dias, uma fase latente dos microrganismos, para logo mais uma fase logarítmica que atinge o seu climax aos 6 dias, no Gráfico II. Verifica-se, também, essa mesma fase logarítmica, êsse pico de 6 dias, no Gráfico I. Essa fase latente é menos pronunciada no Gráfico IV.

\section{CONCLUSÓES}

Os resultados obtidos permitem estabelecer certa correlação entre o solo Latosol Vermelho Amarelo, com e sem cobertura morta, creditando à prática agrícola da cobertura morta certas vantagens que nos obrigam a dar-lhe o lugar devido para a manutenção da fertilidade e da conservação de um solo do tipo usado. 
Por enquanto, o aspecto fragmentário de nosso estudo nos proibe tirar qualquer conclusão formal. No futuro, de posse de dados relacionados com os demais tipos de solo, poderemos obter conclusões mais concretas a respeito.

A interpretação dos indices da atividade proteolitica e amonificante não nos fornece resultaos absolutos, mas nos parecem ser uma bôa expressão da intensidade e da qualidade da atividade biológica dos solos.

\section{SUMARIO}

Os autores estudam, no presente trabalho, um solo tipo Latosol Vermelho Amarelo, com e sem cobertura morta, em 2 profundidades diferentes.

Concluiram sôbre as vantagens de se manter um solo com cobertura morta que permite um aumento da microflora total e dos elementos nutritivos, confirmado pelo pronunciado indice de atividade protelítica e amonificante do solo.

\section{RÉSUMÉ ET CONCLUSIONS}

Les auteurs ont mesuré l'activité protéolytique et amonifiante d'un sol latéritique de l'Etat de São Paulo (Brésil) avec e sans paillis. Ils ont choisi, à cet effet, des échantillons à deux profundeurs différentes: $0-2 \mathrm{~cm}$. et $0-20 \mathrm{~cm}$.

Ils ont démontré, à la suite des résultats obtenus, les avantages du paillis sur ce type de sol. D'ailleurs, on n'ignore pas l'action bienfaisante du paillis dans le problème de la conservation et de la régénération des sols de la zone tropicale et subtropicale.

Les auteurs ont constaté un accroissement considérable de la microflore totale, une teneur plus ćlevée de la matière organique et des élements minéraux, confirmés par les indices protéolytique te amonifiante dans le sol sous paillis. Ces différences ont été encore beaucoup plus sensibles quand on compare les échantillons de sol tirés à une profondeur de $0-2 \mathrm{~cm}$.

\section{LITERATURA CITADA}

CATANI, R. A., J. R. GALLO e H. GARGANTINI, 1955 - Amostragem de solo, métodos de análise. Interpretação e indicações gerais para fins de fertilidade. Inst. Agr., Boletim n. ${ }^{\bullet} 69$.

CROCOMO, O. J. e L. N. MENARD, 1959 - Ciclo do Nitrogênio. Piracicaba, Apost. Mimeog., pág. 11.

WAKSMAN,S., 1922 - Microbiological analysis of soil as an index of soil fertility. III. Influence of fertilization upon numbers of microorganisms in the soil. Soil Sci., 14: 321-346. 